\title{
High recovery of cell-free methylated DNA based on a rapid bisulfite-treatment protocol
}

\author{
Inge Søkilde Pedersen ${ }^{1 *}$, Henrik Bygum Krarup ${ }^{1}$, Ole Thorlacius-Ussing ${ }^{2}$ and Poul Henning Madsen ${ }^{1}$
}

\begin{abstract}
Background: Detection of cell-free methylated DNA in plasma is a promising tool for tumour diagnosis and monitoring. Due to the very low amounts of cell-free DNA in plasma, analytical sensitivity is of utmost importance. The vast majority of currently available methods for analysing DNA methylation are based on bisulfite-mediated deamination of cytosine. Cytosine is rapidly converted to uracil during bisulfite treatment, whereas 5methylcytosine is only slowly converted. Hence, bisulfite treatment converts an epigenetic modification into a difference in sequence, amenable to analysis either by sequencing or PCR based methods. However, the recovery of bisulfite-converted DNA is very poor.
\end{abstract}

Results: Here we introduce an alternative method for the crucial steps of bisulfite treatment with high recovery. The method is based on an accelerated deamination step and alkaline desulfonation in combination with magnetic silica purification of DNA, allowing preparation of deaminated DNA from patient samples in less than 2 hours.

Conclusions: The method presented here allows low levels of DNA to be easily and reliably analysed, a prerequisite for the clinical usefulness of cell-free methylated DNA detection in plasma.

\section{Background}

Bisulfite induced modification of nucleic acids was originally described in the 1970s [1-3] and since the emergence of PCR and sequencing based detection methods $[4,5]$ bisulfite treatment has played a pivotal role in the analysis of DNA methylation. In its original form it is a time consuming and labour intensive procedure involving numerous experimental steps: DNA denaturation, treatment with bisulfite for 12-16 hr, desalting and desulfonation with $\mathrm{NaOH}$, and finally neutralisation and desalting. Recently published improvements include an accelerated deamination step, cutting down incubation time from 12-16 hr to $40 \mathrm{~min}$, achieved by the use of a more concentrated bisulfite solution at higher temperatures [6,7]. The accelerated and the conventional methods have been explicitly compared by Genereux et al. [8]. The accelerated method leads to a more homogenous conversion of cytosine both across sites and molecules, conceivably due to facilitation of DNA

\footnotetext{
* Correspondence: isp@rn.dk

'Section of Molecular Diagnostics, Department of Clinical Biochemistry, Aalborg University Hospital, Denmark, DK

Full list of author information is available at the end of the article
}

denaturation in concentrated bisulfite solution at $70^{\circ} \mathrm{C}$. Hence, inappropriate conversion of 5-methylcytosine, a result of prolonged bisulfite exposure of molecules with complete conversion of cytosine, is more controllable.

In addition to deamination of cytosine, bisulfite also induces chain breakage of DNA [9]. The DNA degradation caused by bisulfite treatment results in DNA fragments of an average length of approximately 600 nucleotides [10]. Real-time PCR based methods rely on amplification of short DNA fragments of 60-150 nucleotides. Hence, the use of real-time PCR limits the direct influence of fragmentation on the detection step. However, fragmentation affects recovery of DNA after bisulfite treatment. If the starting material is < $200 \mathrm{ng}$ DNA, more than $95 \%$ of bisulfite-treated DNA is lost during desulfonation and purification with standard procedures $[10,11]$. This is a serious problem, especially when analysing material with very small amounts of DNA available, such as plasma with a median level of $10 \mathrm{ng}$ cellfree DNA/ml in normal controls [11]. Although, the level of cell-free DNA is slightly increased in cancer patients [12], the combination of minute amounts of cell-free DNA in plasma and poor recovery after 
bisulfite treatment may lead to stochastic sampling issues. Improved recovery can be achieved by incorporation of DNA into agarose prior to bisulfite treatment. Denaturation, deamination and desulfonation are subsequently carried out on DNA embedded in the agarose beads [13]. This method has successfully been used to analyse DNA from microdissected cells [14]. Embedding of DNA in agarose is, however, a labour intensive method not amneable to automation, limiting its suitability in a clinical setting.

The ability to easily analyse sparse amounts of methylated DNA is a prerequisite for the usefulness of cellfree methylated DNA in plasma as a diagnostic or prognostic marker for cancer. An enormous amount of work has been put into identification of putative methylated DNA biomarkers and optimisation of the final analytical step: the detection of bisulfite-treated DNA. Hence, several reliable methods enabling the detection of minute amounts of bisulfite-treated DNA have been published [15-20]. Most recently the qMAMBA protocol (quantitative Methylation Analysis of Minute DNA amounts after whole Bisulfitome Amplification) has been developed, elegantly addressing several of the issues related to methylation analysis of samples with very low amounts of starting material $[19,20]$. However, as stated by Paliwal et al. [19] the most critical determinant of successful application of qMAMBA is the quality and quantity of starting material, emphasising the importance of the initial steps of the analysis: DNA isolation and bisulfitetreatment. Very few studies have addressed the loss of analytical sensitivity associated with the bisulfite treatment itself. Here we present a fast and reliable method, optimised in order to achieve high recovery, for the detection of methylated DNA from biospecimens with sparse amounts of DNA.

\section{Methods}

\section{Bisulfite treatment}

Cell-free DNA was isolated from $1 \mathrm{ml}$ EDTA plasma on the EasyMAG nucleic acid purification platform (Biomeriéux), using the recommended protocol for plasma.

Bisulfite treatment was based on previously published accelerated methods $[6,7]$, with some modifications. The optimised protocol is as follows: $50 \mu \mathrm{l}$ of $10 \mathrm{M}\left(\mathrm{NH}_{4}\right)$ $\mathrm{HSO}_{3}-\mathrm{NaHSO}_{3}$ solution were added to $25 \mu \mathrm{l}$ of purified DNA in PCR strips. The strips were placed in a PCR machine, heated for $10 \mathrm{~min}$ at $90^{\circ} \mathrm{C}$ and subsequently cooled to room temperature. The solution containing the DNA-bisulfite adducts were purified on the EasyMAG nucleic acid purification platform (Biomeriéux) using the off-board procedure according to manufacture's instructions, except for changes made to lysis buffer, extraction buffers A and B, and elution buffer. To ensure high recovery, $2 \mathrm{ml}$ EasyMAG lysis buffer were replaced by a mix of $0.5 \mathrm{ml}$ ethanol and $0.5 \mathrm{ml} \mathrm{H}{ }_{2} \mathrm{O}$, whereas extraction buffers $\mathrm{A}$ and $\mathrm{B}$ (Biomeriéux) both were replaced by $33 \%$ ethanol in $\mathrm{H}_{2} \mathrm{O}$. For this extraction $25 \mu \mathrm{l}$ magnetic beads were used. Finally, DNA was eluted in $25 \mu \mathrm{l} 10 \mathrm{mM} \mathrm{KOH}$. The alkaline solution in combination with the heating occurring during elution leads to desulfonation of DNA-bisulfite adducts.

\section{DNA quantitation}

To investigate recovery of bisulfite-treated DNA, 3 different primersets, all sharing the same detection probe, were designed: MLH1UF and MLH1 R detect DNA regardless of deamination [11]. MLH1 DF and MLH1 R detect deaminated DNA, whereas MLH1 UDF and MLH1 UDR detect undeaminated DNA (Table 1 and Figure 1B).

\section{Dynamics of deamination}

Three $\mu \mathrm{g}$ of colon tissue DNA were deaminated in triplicate for different time durations, purified and desulfonated. Five ul DNA were used for quantitation, the residual DNA was used for HPLC. This DNA was digested with 1 unit nuclease P1 (Sigma) and 10 units DNAseI (Roche) in a total volume of $40 \mu \mathrm{l}$ at $37^{\circ} \mathrm{C}$ overnight [21]. Two units alkaline phosphatase (Roche) were added and the mix was incubated at $37^{\circ} \mathrm{C}$ for 2 hours. Before injection, $50 \mu \mathrm{l}$ of $50 \mathrm{mM}$ sodium acetate $\mathrm{pH} 4.8$ were added. Twentyfive $\mu \mathrm{l}$ were injected into a cation exchange column (Luna SCX, Phenomenex) in a Dionex Ultimate 3000 HPLC system. The mobile phase consisted of $5 \%$ acetonitrile in a gradient of $50 \mathrm{mM}$ sodium acetate from $2 \%$ to $75 \%$. Deoxynucleosides were detected at $260 \mathrm{~nm}$. For calculation of relative amounts of nucleosides the following extinction coefficients have been used: $\mathrm{dU}\left(9.2^{*} 10^{3} \mathrm{M}^{-1} \mathrm{~cm}^{-1}\right)$, dT $\left(9.2^{*} 10^{3} \mathrm{M}^{-1} \mathrm{~cm}^{-}\right.$ $\left.{ }^{1}\right)$, dG $\left(11.7^{*} 10^{3} \mathrm{M}^{-1} \mathrm{~cm}^{-1}\right)$, dA $\left(15.4^{*} 10^{3} \mathrm{M}^{-1} \mathrm{~cm}^{-1}\right), \mathrm{dC}$ $\left(7.5^{*} 10^{3} \mathrm{M}^{-1} \mathrm{~cm}^{-1}\right)$ and $\mathrm{dmC}\left(7.5^{*} 10^{3} \mathrm{M}^{-1} \mathrm{~cm}^{-1}\right)$.

\section{Measurement of analytical sensitivity}

The sensitivity of methylation detection was assessed by analysing a dilution series of Universal Methylated DNA (Chemicon) in purified plasma DNA. After deamination the recovered DNA was quantified in triplicate for methylated RASFF1A and unmethylated RASSF1A using primers and probes listed in Table 1.

The efficiency of the deamination of unmethylated cytosines and the recovery of both methylated and unmethylated DNA fragments following bisulfite-treatment were elucidated using the hemimethylated MEST promoter as a model. Plasma DNA was diluted to concentrations of 10, 5, 2.5 and 1.25 genome equivalents pr. $25 \mu \mathrm{l}$ of methylated and unmethylated MEST, respectively. Twentyfour samples of each dilution were deaminated and used in methylation-specific real-time PCR 
Table 1 Primer and beacon sequences

\begin{tabular}{ll}
\hline Primer/beacon & Sequence \\
\hline MLH1 UF & TGT GAI AAA AAA TGT GAA GGG \\
\hline MLH1 DF $R$ & GAA GAT ATT AGA TTT TAT GGG TTA TTT \\
\hline MLH1 UDF & CAA CTI AAT TTT AAC AAA ATA ATC T \\
\hline MLH1 UDR & ACC AGA TTT TAT GGG TCA TCC \\
\hline MLH1 beacon & TTC TAT TAA CGT ACG GAC G \\
\hline RASSF1A MF & (FAM)CGC GAA TGT GGA AGG AAA AGT GAG TGT CGC(Dabcyl) \\
\hline RASSF1A MR & GGG AGG CGT TGA AGT C \\
\hline RASSF1A M beacon & CCC GTA CTT CGC TAA CTT TAA ACG \\
\hline RASSF1A UMF & (HEX)CGC GAT TCG + TT + C G + GT TCG CTC GCG(Dabcyl) \\
\hline RASSF1A UMR & TTT TGT ATT TAG GTT TTT ATT GTG T \\
\hline RASSF1A UM beacon & CCC ATA CTT CAC TAA CTT TAA ACA \\
\hline MEST MF & (FAM)CGC GAG + TT + TG + GTT + TG + TG + TTC GCG(Dabcyl) \\
\hline MEST MR & TGT CGC GGT AAT TAG TAT ATT TC \\
\hline MEST M beacon & AAC CCG CGC AAA ACG ACG \\
\hline MEST UMF & (HEX)CGC GAT TAC + GAA AC + G CAA CTA CCG ATC GCG(Dabcyl) \\
\hline MEST UMR & GTG TTG TTG TGG TAA TTA GTA TAT TTT \\
\hline MEST UM beacon & AAC CCA CAC AAA ACA ACA CCA \\
\hline MLH1 UF and MH R CAM CAG + TA + G T + TG + TG + T TT + T GTT CGC G(Dabcyl)
\end{tabular}

MLH1 UF and MLH1 R concurrently amplify deaminated and undeaminated MLH1 promoter. MLH1 DF and MLH1 R amplify deaminated MLH1. MLH1 UDF and MLH1 UDR amplify undeaminated MLH1 promoter. A common molecular beacon (MLH1 beacon) was used for detection of the 3 products. RASSF1A MF and RASSF1A MR amplify methylated RASSF1A. RASSF1A UMF and RASSF1A UMR amplify unmethylated RASSF1A. Methylated and unmethylated products were detected by RASSF1A M beacon and RASSF1A UM beacon, respectively. MEST MF and MEST MR amplify methylated MEST, whereas MEST UMF and MEST UMR amplify unmethylated MEST. Methylated and unmethylated products were detected by MEST M beacon and MEST UM beacon, respectively. To ensure high specificity the probes designed to discriminate between methylated and unmethylated products contain LNA nucleotides at positions marked with +.

with MEST UM primers and probe and MEST M primers and probe, respectively. Primer and probe sequences are listed in Table 1 . The detection frequencies were calculated as the percentage of positive reactions out of the 24 replicates.

\section{Measurement of recovery}

Recovery of deaminated plasma DNA was investigated using DNA from 24 plasma samples. DNA from $1 \mathrm{ml}$ of each sample was extracted and eluted in 75 ul. Twentyfive ul were deaminated and extracted, another $25 \mathrm{ul}$ were mock-deaminated (no heating) and extracted, whereas the residual was used for quantitation using $M L H 1$ primers described in Table 1.

\section{Results and discussion}

Extensive optimisation of a previously published bisulfite treatment method [6,7] has led to the development of a fast bisulfite treatment with high recovery and potential for semi-automation. Optimisation involved the purification procedure after deamination in order to facilitate recovery of the fragmented DNA resulting from bisulfite treatment. This part of the procedure has previously been identified as a critical step [10]. Optimisation of the purification method had a pronounced effect on recovery, especially replacement of lysis and extraction buffers with ethanol increased recovery. In addition, adjustments of the reaction time were made. During optimisation the dynamics of the reaction had to be measured in order to ensure optimal conversion of cytosine and limited conversion of methyl-cytosine.

In the discovery phase bisulfite treatment, cloning and sequencing of individual clones is the method of choice, because of the detailed information of methylation status of individual CpG sites achieved. This procedure, from primer design to presentation of results has been described in detail [22]. When sequencing individual clones, complete deamination of unmethylated cytosine is extremely important. Incomplete deamination of unmethylated cytosine could lead to a false positive result. Typically more than one methylated CpG site is investigated when using methylated DNA as a tumour marker. Hence, this set up is less likely to yield a false positive result due to incomplete conversion of cytosine. However, if the reaction is poorly optimised and conversion of cytosine is far from complete, real-time detection will fail, leading to apparently low recovery. Therefore, while optimising recovery, dynamics of the reaction have been extensively monitored using both a real-time PCR based and a HPLC based method. The results of optimisation of the reaction time are shown in Figures 1 and 2. After $5 \mathrm{~min}$ of deamination, no undeaminated 


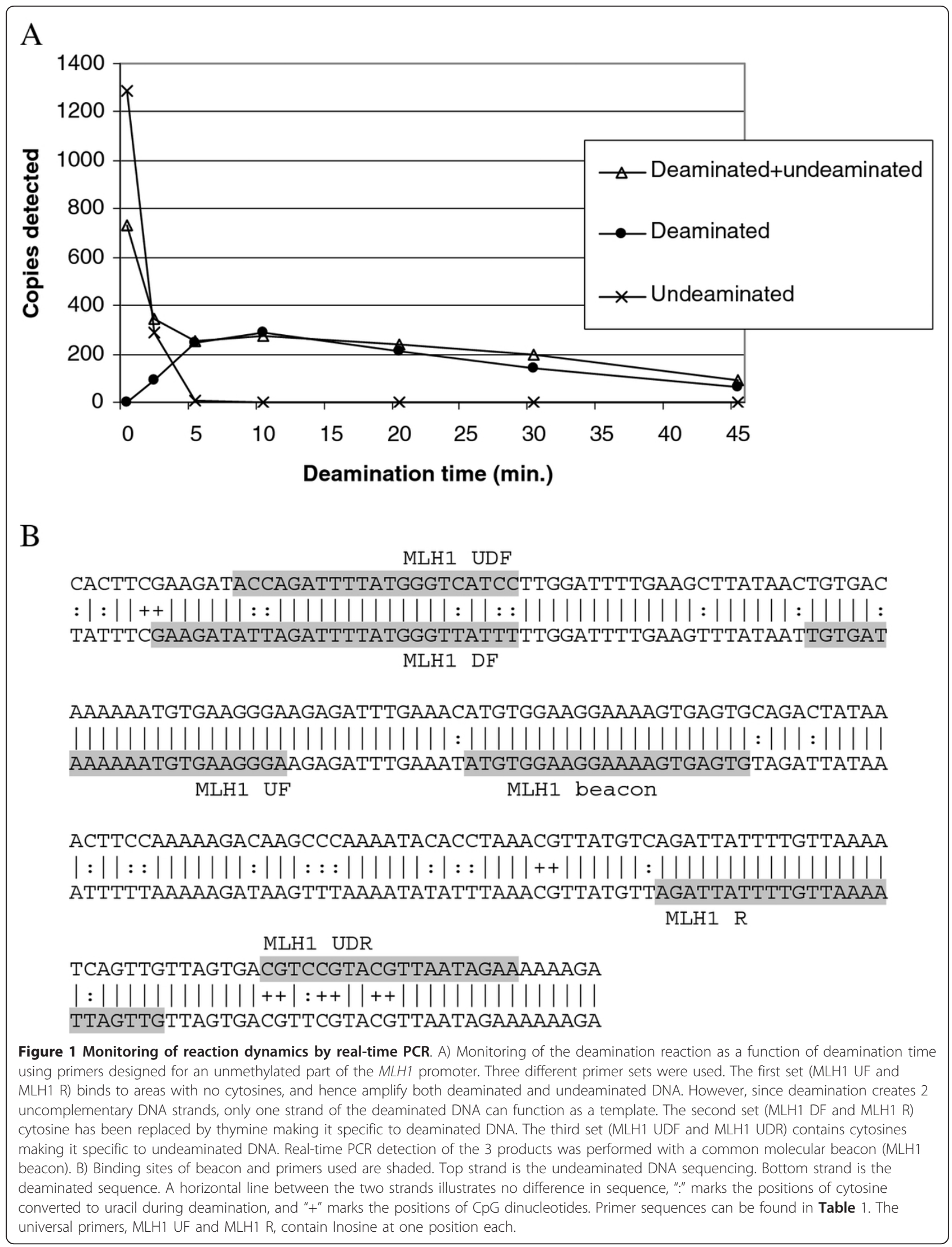




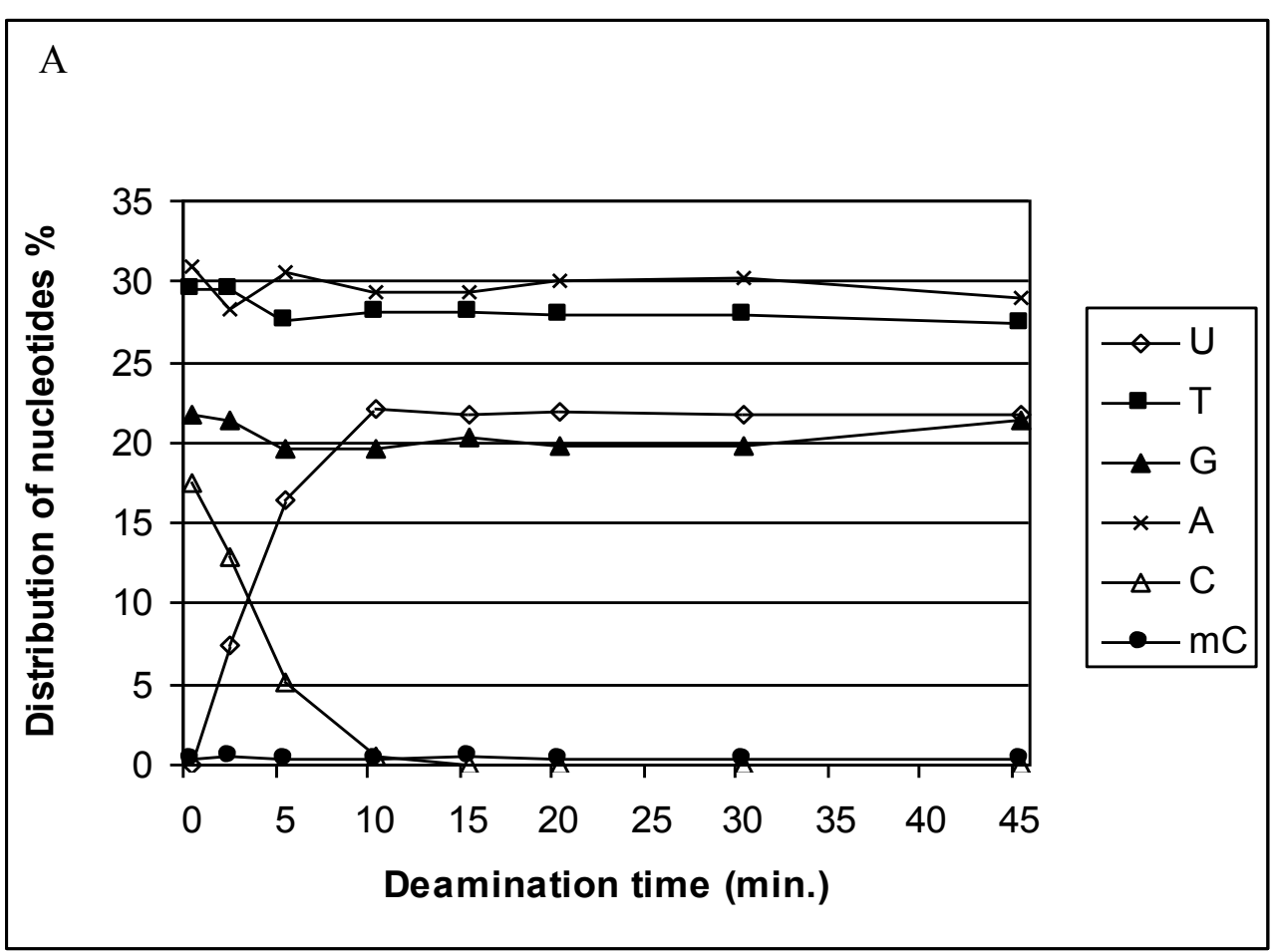

\section{$\mathrm{B}$}

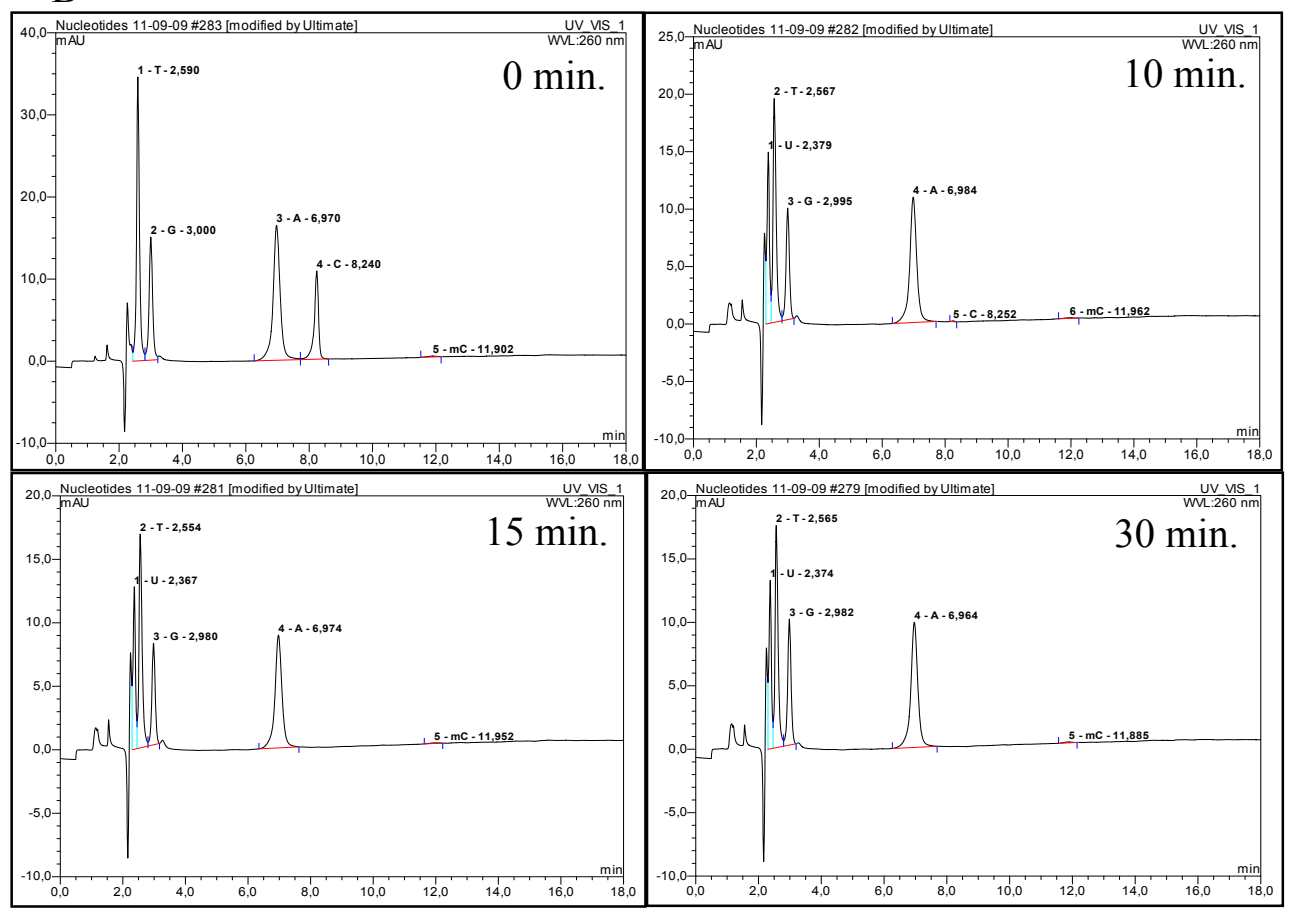

Figure 2 Monitoring of reaction dynamics by HPLC. A) The distribution of nucleosides as measured by HPLC depicted as a function of deamination time. The levels of Gs, As and methylated Cs remain constant throughout the reaction. Cs are converted to Us as the deamination progresses. B) Examples of HPLC chromatograms at different deamination times (0 min., 10 min., 15 min. and 30 min.).

product was detectable by real-time PCR (Figure 1). The beacon and primers used in this experiment have been designed in order to give as comparable reaction conditions as possible. The overlap in the probe and primers used for the different reactions gives less stringent differentiation compared with methylation specific real- 
time PCR, where both primers and probes generally are specific for either the methylated or the unmethylated sequence. However, no cross-reactivity is observed in our experiment. The primers used to discriminate between undeaminated and deaminated product cover 5 cytosines (Figure 1). Primer binding mainly depends on the conversion of the 2 cytosines in the 3' end of the primer binding site. Therefore complete conversion of cytosine appears to be achieved faster when measured by real-time PCR compared with HPLC, where a limited amount of cytosines $(<1 \%)$ is detectable after $10 \mathrm{~min}$ deamination, and none after 15 min (Figure 2). Longer deamination time than $10 \mathrm{~min}$ results in reduced detection of both deaminated and undeaminated DNA, since the purpose is to optimise this protocol in order to achieve the best possible recovery of bisulfite treated DNA, the deamination time was set to $10 \mathrm{~min}$.

In addition to incomplete conversion of cytosine, inappropriate conversion of methylated cytosine could lead to reduced sensitivity when detecting methylated DNA. The real-time PCR based experiment (Figure 1) does not address the problem of over-conversion, since the primers and the probe are designed to an unmethylated part of $M L H 1$. Methylated cytosine is monitored by the HPLC procedure (Figure 2). However, methylated cytosine constitutes only a small fraction of the nucleotides. Therefore, to further elucidate the reaction dynamics and recovery of both methylated and unmethylated DNA, the hemimethylated MEST promoter has been used as a naturally occurring model system. Comparable detection of methylated and un-methylated MEST was observed, when calculating detection frequency as the percentage of positive reactions out of the 24 replicates (Figure 3).

Similar experiments monitoring the dynamics of the reaction were carried out when changing other parameters, such as reaction temperature and denaturation

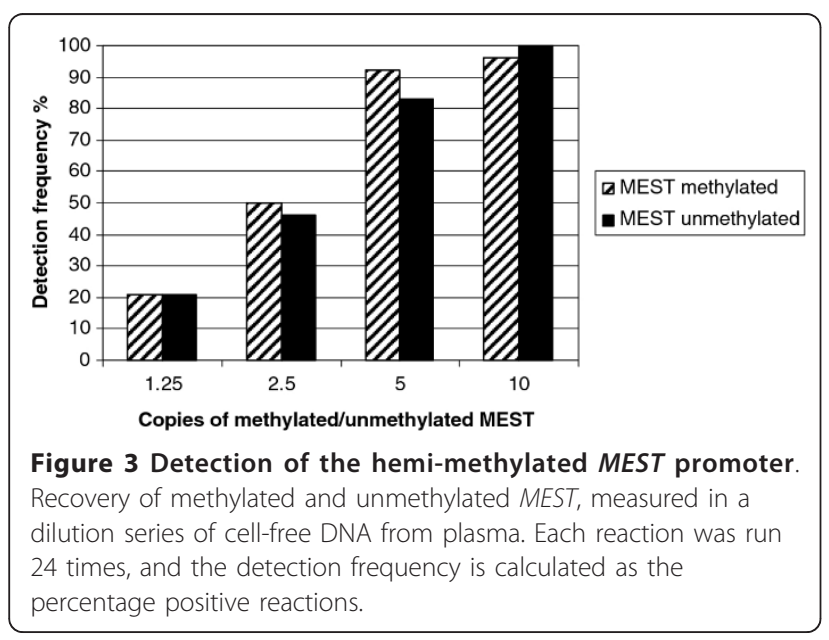

of DNA prior to bisulfite treatment (data not shown). Denaturation of DNA did not affect recovery or conversion in the current study, even though this step has been pointed out to be critical, and different denaturants such as $\mathrm{NaOH}$, urea and formamide have been used. Formamide was shown to have a great effect when working on DNA from formalin-fixed paraffinembedded tissue [23]. The lack of need of denaturants in the protocol presented here possibly reflects the denaturating effect of the high concentration of bisulfite and high temperature used for deamination.

Further investigation of the analytical sensitivity of the newly optimised procedure was carried out using a dilution of universally methylated DNA in purified plasma DNA. RASSF1A was used as a model system. RASSF1A is fully methylated in the universally methylated DNA and unmethylated in the plasma DNA sample. Table 2 illustrates that low copy numbers of methylated RASSF1A promotor region was reliably detected in a background of approximately 2000 copies of unmethylated DNA.

Recovery of deaminated DNA using the optimised method was compared with recovery of DNA in a matrix of deamination reagents. Re-extraction of DNA in a matrix of deamination reagents results in a recovery of $83 \%$ whereas recovery of deaminated DNA is $60 \%$ (Table 3). The likely explanation of the difference is the unavoidable degradation of DNA during deamination.

Markers such as septin 9 hold great promise of clinical usefulness. The improved recovery rate of the bisulfite reaction achieved by the presented protocol may further improve its potential in a clinical setting, and avoid some of the expensive and labour intensive steps such as the need to purify multiple plasma samples in parallel and subsequent pooling of DNA $[16,24]$. Indeed, the initial promising reports on the potential of septin 9 have been strengthened by a recent report employing silica based magnetic DNA purification [25]. This work by deVos et $a l$. address the problem of poor recovery, and the reported recovery rates are comparable to our results. However, the quantitation of DNA prior to and after bisulfite treatment is based on two different real-time PCR assays. We have employed a real-time PCR assay capable of detecting both treated and untreated DNA [11] allowing the same assay to be used for measuring DNA levels both pre and post bisulfite treatment resulting in improved accuracy

\section{Conclusions}

In this report we present a fast and reliable bisulfite treatment with high recovery from samples with minute amounts of DNA $(<0.1 \mathrm{ng} / \mathrm{ml})$, opening the possibility of improving diagnostic sensitivity of the wide-range of potential markers already identified. The major improvement in recovery is achieved by alterations in the 
Table 2 Detection of methylated DNA diluted in unmethylated DNA

\begin{tabular}{lllllllll}
\hline Copies of methylated DNA & 0 & 1.3 & 4 & 11.9 & 35.6 & 107 & 320 & 960 \\
\hline Detected methylated copies (RASSF1A) & 0 & 0.5 & 4.9 & 11 & 41 & 142 & 328 & 832 \\
\hline Detected unmethylated copies (RASSF1A) & 1748 & 2192 & 2297 & 2207 & 1832 & 2700 & 2285 & 2194 \\
\hline
\end{tabular}

Detection of RASSF1A in a 3-fold dilution series of methylated DNA in a background of 2000 copies of DNA. Top row represents the calculated number of methylated copies of RASSF1A promoter. The following rows represent methylated and unmethylated copies respectively, detected by real-time PCR.

\section{Table 3 Recovery of plasma DNA}

\begin{tabular}{llll}
\hline & Average copy no. (copies/ml plasma) & Median copy no. (copies/ml plasma) & Recovery (\%) \\
\hline Plasma DNA, double stranded & 3629 & 1475 & \\
\hline Mock-deaminated DNA, double stranded & 2830 & 1223 & 83.3 \\
\hline Deaminated DNA, single stranded & 2437 & 667 & 60.5 \\
\hline
\end{tabular}

${ }^{1}$ Recovery has been calculated as the average recovery of 24 individual deamination reactions.

purification of bisulfite treated DNA. In addition, the method presented here allows preparation of deaminated DNA from patient samples in less than 2 hours. The development of this method amenable to semiautomation should considerably enhance the usefulness of methylation analysis in a clinical setting.

\section{Acknowledgements}

We thank Nicola Miller for language revision of the manuscript. This work was supported by "Det Obelske Familiefond" [grant number 26337313].

\section{Author details}

'Section of Molecular Diagnostics, Department of Clinical Biochemistry, Aalborg University Hospital, Denmark, DK. ²Department of Surgical Gastroenterology, Aalborg University Hospital, Denmark, DK.

\section{Authors' contributions}

ISP participated in study design and analysis and drafted the manuscript. HBK and OTU participated in study design and helped to draft the manuscript. PHM participated in study design, carried out the analyses and helped to draft the manuscript. All authors read and approved the final manuscript.

\section{Competing interests}

The authors declare that they have no competing interests.

Received: 17 November 2011 Accepted: 26 March 2012 Published: 26 March 2012

\section{References}

1. Hayatsu H, Wataya Y, Kai K: Addition of Sodium Bisulfite to Uracil and to Cytosine. J Am Chem Soc 1970, 92:724-726.

2. Hayatsu H, Wataya Y, Kai K, lida S: Reaction of Sodium Bisulfite with Uracil Cytosine, and Their Derivatives. Biochem 1970, 9:2858-2865.

3. Shapiro R, Servis RE, Welcher M: Reactions of Uracil and Cytosine Derivatives with Sodium Bisulfite. A Specific Deamination Method. J Am Chem Soc 1970, 92:422-424.

4. Frommer M, Mcdonald LE, Millar DS, Collis CM, Watt F, Grigg GW, Molloy PL, Paul CL: A Genomic Sequencing Protocol That Yields A Positive Display of 5-Methylcytosine Residues in Individual DNA Strands. Proc Natl Acad Sci USA 1992, 89:1827-1831.

5. Herman JG, Graff JR, Myohanen S, Nelkin BD, Baylin SB: Methylationspecific PCR: A novel PCR assay for methylation status of CpG islands. Proc Natl Acad Sci USA 1996, 93:9821-9826.

6. Hayatsu $H$, Negishi K, Shiraishi M: DNA methylation analysis: speedup of bisulfate-mediated deamination of cytosine in the genomic sequencing procedure. Proc Jpn Acad Ser B 2004, 80:189-194.
7. Shiraishi M, Hayatsu $\mathrm{H}$ : High-speed conversion of cytosine to uracil in bisulfite genomic Sequencing analysis of DNA methylation. DNA Res 2004, 11:409-415.

8. Genereux DP, Johnson WC, Burden AF, Stoger R, Laird CD: Errors in the bisulfite conversion of DNA: modulating inappropriate- and failedconversion frequencies. Nucleic Acids Res 2008, 36:e150.

9. Suzuki T, Ohsumib S, Makino K: Mechanistic Studies on Depurination and Apurinic Site Chain Breakage in Oligodeoxyribonucleotides. Nucleic Acids Res 1994, 22:4997-5003.

10. Munson K, Clark J, Lamparska-Kupsik K, Smith SS: Recovery of bisulfiteconverted genomic sequences in the methylation-sensitive QPCR. Nucleic Acids Res 2007, 35:2893-2903.

11. Tanaka K, Okamoto A: Degradation of DNA by bisulfite treatment. Bioorg Med Chem Lett 2007, 17:1912-1915.

12. Leon SA, Shapiro B, Sklaroff DM, Yaros MJ: Free Dna in Serum of CancerPatients and Effect of Therapy. Cancer Res 1977, 37:646-650.

13. Olek A, Oswald J, Walter J: A modified and improved method for bisulphite based cytosine methylation analysis. Nucleic Acids Res 1996, 24:5064-5066

14. Kerjean A, Vieillefond A, Thiounn N, Sibony $M$, Jeanpierre $M$, Jouannet $P$ : Bisulfite genomic sequencing of microdissected cells. Nucleic Acids Res 2001, 29:e106.

15. Dietrich D, Lesche R, Tetzner R, Krispin M, Dietrich J, Haedicke W, Schuster M, Kristiansen G: Analysis of DNA methylation of multiple genes in microdissected cells from formalin-fixed and paraffin-embedded tissues. J Histochem Cytochem 2009, 57:477-489.

16. Grutzmann R, Molnar B, Pilarsky C, Habermann JK, Schlag PM, Saeger HD, Miehlke S, Stolz T, Model F, Roblick UJ, Bruch HP, Koch R, Liebenberg V, DeVos T, Song X, Day RH, Sledziewski AZ, Lofton-Day C: Sensitive detection of colorectal cancer in peripheral blood by septin 9 DNA methylation assay. PLoS One 2008, 3:e3759.

17. Lofton-Day C, Model F, Devos T, Tetzner R, Distler J, Schuster M, Song X, Lesche R, Liebenberg V, Ebert M, Molnar B, Grutzmann R, Pilarsky C, Sledziewski A: DNA methylation biomarkers for blood-based colorectal cancer screening. Clin Chem 2008, 54:414-423.

18. Eads CA, Danenberg KD, Kawakami K, Saltz LB, Blake C, Shibata D, Danenberg PV, Laird PW: MethyLight: a high-throughput assay to measure DNA methylation. Nucleic Acids Res 2000, 28:e32.

19. Paliwal A, Vaissiere T, Herceg Z: Quantitative detection of DNA methylation states in minute amounts of DNA from body fluids. Methods 2010, 52:242-247.

20. Vaissiere T, Cuenin C, Paliwal A, Vineis P, the Genair-EPIC Investigators, Hainaut P, Herceg Z: Quantitative analysis of DNA methylation after whole bisulfitome amplification of a minute amount of DNA from body fluids. Epigenetics 2009, 4:221-230

21. Shimelis O, Giese RW: Nuclease P1 digestion/high-performance liquid chromatography, a practical method for DNA quantitation. J Chromatogr A 2006, 1117:132-136.

22. Zhang Y, Rohde C, Tierling S, Stamerjohanns, Reinhardt R, Walter J, Jeltsch A: DNA methylation analysis by bisulfite conversion, cloning, and sequencing of individual clones. Methods Mol Biol 2009, 507:177-187. 
23. Zon G, Barker MA, Kaur P, Groshen S, Jones LW, Imam SA, Boyd VL:

Formamide as a denaturant for bisulfite conversion of genomic DNA:

Bisulfite sequencing of the GSTPi and RAR 32 genes of 43 formalin-fixed paraffin-embedded prostate cancer specimens. Anal Biochem 2009, 392:117-125.

24. Tetzner R, Dietrich D, Distler J: Control of carry-over contamination for PCR-based DNA methylation quantification using bisulfite treated DNA Nucleic Acids Res 2007, 35:e4.

25. deVos T, Tetzner R, Model F, Weiss G, Schuster M, Distler J, Steiger KV, Grutzmann R, Pilarsky C, Habermann JK, Fleshner PR, Oubre BM, Day R, Sledziewski AZ, Lofton-Day C: Circulating Methylated SEPT9 DNA in

Plasma Is a Biomarker for Colorectal Cancer. Clin Chem 2009, 55:1337-1346.

doi:10.1186/1471-2199-13-12

Cite this article as: Pedersen et al: High recovery of cell-free methylated DNA based on a rapid bisulfite-treatment protocol. BMC Molecular Biology 2012 13:12.

\section{Submit your next manuscript to BioMed Central} and take full advantage of:

- Convenient online submission

- Thorough peer review

- No space constraints or color figure charges

- Immediate publication on acceptance

- Inclusion in PubMed, CAS, Scopus and Google Scholar

- Research which is freely available for redistribution

Submit your manuscript at www.biomedcentral.com/submit 